\title{
Reciclagem de agarose em laboratórios de biologia molecular
}

\author{
Recycling agarose in molecular biology laboratories
}

\section{Lia Rejane Silveira Reiniger ${ }^{1}$ Denilson Anthonisen ${ }^{2}{\text { Eva } \text { Choer }^{3} \text { Lenira Maria Nunes Sepel }}^{4}$}

\section{- NOTA -}

\section{RESUMO}

Em laboratórios de biologia molecular, a eletroforese em gel de agarose é usada, rotineiramente, para separar moléculas de ácidos nucléicos. A agarose é um polímero extraído de algas marinhas que apresenta custo elevado. O objetivo do presente trabalho consistiu na otimização de um protocolo de reciclagem deste produto, após proceder a descontaminação de brometo de etídio, possibilitando sua reutilização em eletroforese analítica. $O$ processo, originalmente proposto por PALACIOS et al. (2000), recebeu modificações e consistiu em equilibrar a agarose em água, efetuar sua secagem e transformá-la novamente em pó, em moinho. $O$ produto reciclado assemelhou-se ao original, apresentando grânulos ligeiramente maiores e mais escuros. Os géis foram preparados da mesma maneira que usando o produto original, não requerendo nenhum procedimento adicional. A agarose reciclada ficou disponível para uso imediato, podendo ser armazenada à temperatura ambiente, por longos períodos de tempo e ocupando uma pequena área. Presta-se à elaboração de géis analíticos das mais variadas concentrações e composições de tampão. Além disso, a reciclagem também contribui para a diminuição de resíduos sólidos descartados no meio ambiente e resulta em significativa redução de custos. Os géis com o produto reciclado mostraram desempenho semelhante na eletroforese e possibilitaram uma adequada resolução das bandas.

Palavras-chave: eletroforese, matriz gélica, melhoria de processos.

\section{ABSTRACT}

In molecular biology laboratories, the agarose gel electrophoresis is used on a daily basis in order to separate nucleic acid molecules. The agarose is a polimere of elevated cost. The goal of the present work consisted in the optimization of a protocole of agarose recycling, transforming it, once again, into a powdery material si- milar to the original, after performing the decontamination of ethidium bromide, allowing its reuse in analitycal electrophoresis. The process, originally proposed by PALACIOS et al. (2000) receveid modifications and consisted in balancing the agarose in water, drying and milling $i t$. The recycled agarose resembled the original, presenting slightly bigger and darker granules. The recycled agarose was avaliable for imediate use, being storegeable at room temperature, for wide periods of time and taking up very few space. It is fit for the manufacturing of analytical gels of the widest brand of concentrations and buffer compositions. Besides, recycling also contributes to the diminution of solid waste disposed in the enviroment and results in significant reduction of costs. The manufaturing of gels took place in a similar way as with the original product, not recquiring any aditional procedure. The recycled gels showed similar performance in electrophoresis and allowed and adequate resolution of bands.

Key words: electrophoresis, gellic matrix, process improvement.

A separação de moléculas de ácidos nucléicos em laboratórios de biologia molecular é realizada com o auxílio da técnica de eletroforese em gel de agarose (AZEVEDO et al., 2003; MIESFELD, 1999). A agarose é proveniente de algas marinhas e apresenta custo elevado (DE-SOUZA, 2003).

Os géis de agarose são, geralmente, corados com soluções de brometo de etídio (EtBr), uma substância intercalante de alta toxicidade e mutagenicidade, que revela os ácidos nucléicos ao fluorescer sob luz ultravioleta (WHITE et al., 1998). Para evitar danos à saúde humana e ao meio ambiente, os resíduos sólidos e líquidos que contêm EtBr

${ }^{1}$ Engenheiro Agrícola, Doutor, Professor, Departamento Fitotecnia, Universidade Federal de Santa Maria (UFSM), Campus Universitário, 97105-900, Santa Maria, RS. E-mail: reiniger@terra.com.br. Autor para correspondência.

${ }^{2}$ Bacharel em Química, Assistente de Operações, Embrapa Clima Temperado, Pelotas, RS.

${ }^{3}$ Engenheiro Agrícola, Doutor, Pesquisador, Embrapa Clima Temperado, Pelotas, RS.

${ }^{4}$ Biólogo, Mestre, Professor, Departamento Biologia, UFSM. 
somente deve ser realizado após sua prévia descontaminação (DE-SOUZA, 2003).

O objetivo do presente trabalho consistiu na otimização de um protocolo de reciclagem de agarose, transformando-a novamente em pó, semelhante à original, após proceder à descontaminação de EtBr, passível de ser reutilizada em eletroforese analítica.

A otimização do protocolo de reciclagem de agarose foi desenvolvida no Laboratório de Eletroforese da Embrapa Clima Temperado, em Pelotas, RS, durante o ano de 2002.

Para a descontaminação de resíduos contendo EtBr utilizou-se o procedimento descrito por LUNN \& SANSONE (1987), aplicável a soluções de concentração inferior a $0,5 \mathrm{mg} \cdot \mathrm{ml}^{-1} \mathrm{em}$ água, tampões TBE e MOPS, e gradientes de $\mathrm{CsCl}$. A solução descontaminante foi constituída de $20 \mathrm{ml}$ de uma solução a 5\% de ácido hipofosforoso e $12 \mathrm{ml}$ de uma solução $0,5 \mathrm{M}$ de nitrito de sódio. Para o tratamento dos resíduos líquidos foi empregada uma proporção 3:1 de solução descontaminante e resíduo respectivamente, sendo mantida esta mistura em repouso por $20 \mathrm{~h}$. Decorrido esse período, foram adicionados 850 $900 \mathrm{ml}$ de uma solução $1 \mathrm{M}$ de bicarbonato de sódio de modo a ajustar o pH para 6,0-7,0. Após a neutralização, a mistura foi descartada como resíduo não perigoso. Para os géis, utilizou-se um volume de solução suficiente para cobrir totalmente sua superfície, deixando-os em repouso por $20 \mathrm{~h}$. Na seqüência, a solução foi decantada, sendo neutralizada como descrito anteriormente, e iniciou-se o processo de reciclagem.

O procedimento utilizado para reciclar a agarose baseou-se no protocolo de PALACIOS et al. (2000), o qual recebeu modificações para adaptar-se à semana de cinco dias de trabalho e à infraestrutura do Laboratório, sendo incluída a etapa de moagem dos fragmentos de gel após a secagem.

Géis de agarose de variadas concentrações, já analisados, armazenados em geladeira há alguns dias, foram depositados em um recipiente plástico e reduzidos, com o auxílio de uma espátula, a fragmentos das menores dimensões possíveis. Sobre estes foi adicionado um volume de água de torneira suficiente para cobrir a agarose a ser reciclada. Para ajustar o protocolo à semana de trabalho, iniciou-se esta etapa em uma sexta-feira. Neste primeiro dia e nos próximos dois (final de semana), os fragmentos foram mantidos em repouso, à temperatura ambiente. De acordo com PALACIOS et al. (2000), 24h seriam suficientes.

$\mathrm{Na}$ manhã do quarto dia, a água foi decantada e substituída por idêntico volume de água fresca, da mesma procedência, permanecendo por mais $24 \mathrm{~h}$. Seguiu-se a esta uma nova troca de água, repetindo-se o procedimento anterior. No sexto e sétimo dias repetiram-se as substituições, usandose, porém, água destilada, totalizando cinco trocas de água.

Na manhã do oitavo dia, após retirar-se o excesso de água, os fragmentos foram acondicionados em uma bandeja e colocados a secar em estufa a $60^{\circ} \mathrm{C}$, sendo revolvidos, manualmente, em intervalos de $3 \mathrm{~h}$. No final da tarde, a estufa foi desligada e a bandeja, mantida em seu interior durante os dois dias seguintes. Todos os resíduos líquidos foram descontaminados antes de seu descarte.

Dez dias após o início do processo, os fragmentos, totalmente secos, foram pulverizados em moinho e armazenados em frascos plásticos com tampa sob condições ambientais. A agarose reciclada assemelhou-se à original, apresentando grânulos ligeiramente maiores e um pouco mais escuros.

A secagem sob agitação, em estufa provida de ventilação forçada certamente agilizaria a reciclagem, poderia reduzir os fragmentos e, em conseqüência, o tamanho dos grânulos.

Imediatamente após a moagem, a agarose tornou-se disponível para uso e armazenamento à temperatura ambiente, por longos períodos de tempo e ocupando pequenas áreas. Presta-se à confecção de géis analíticos das mais variadas concentrações e composições de tampões. Além disso, a reciclagem também contribui para a redução de resíduos descartados no meio ambiente e de custos nos laboratórios de pesquisa e prestação de serviços.

Os géis de agarose reciclada foram preparados da mesma maneira que aqueles formados com o produto original, não requerendo nenhum procedimento adicional. Os géis mostraram semelhante desempenho na eletroforese e possibilitaram uma adequada resolução das bandas.

A viabilidade de execução desse protocolo, em outros laboratórios, foi avaliada, posteriormente, no Núcleo de Biotecnologia Aplicada à Produção Vegetal, do Centro de Ciências Rurais, e no Laboratório de Biologia Molecular, do Centro de Ciências Naturais e Exatas, da Universidade Federal de Santa Maria, resultando em sucesso similar. Atualmente, a possibilidade de reciclar, mais quatro vezes, géis elaborados com agarose recuperada por este processo, sugerida por PALACIOS et al. (2000), também vem sendo testada nesses laboratórios. 


\section{REFERÊNCIAS BIBLIOGRÁFICAS}

AZEVEDO, M.O. et al. (Org.) Técnicas básicas em biologia molecular. Brasília : UNB, 2003. 211p.

DE-SOUZA, M.T. Análise de DNA por eletroforese em gel de agarose. In: AZEVEDO, M.O. et al. (Org.) Técnicas básicas em biologia molecular. Brasília : UNB, 2003. p.11-128.

LUNN, G.; SANSONE, E.B. Ethidium bromide: destruction and decontamination of solutions. Analytical Biochemistry, London, v.162, n.2 , p.453, 1987.
MIESFELD, R.L. Applied molecular genetics. WileyLiss : New York, 1999. 293p.

PALACIOS, G.; GIMÉNEZ, C.; GARCIA, E. Recycling agarose. Plant Molecular Biology Reporter, v.18, n.1, p.47-49, 2000. On line. Disponível em http:/www.nrc.ca/cisti/journals/ ispmb/reporter.html

WHITE, P.S. et al. Mitochondrial DNA isolation, separation, and detection of fragments. In: HOELZEL, A.R. Molecular genetic analysis of populations - a practical approach. Oxford : IRL, 1998. p.65-101. 